\title{
Demand Responsive Transport: A Review of Schemes in England and Wales
}

\author{
Rebecca Laws, Marcus Enoch, Stephen Ison \\ Loughborough University
}

Stephen Potter, The Open University

\begin{abstract}
Local-authority-administered Demand Responsive Transport (DRT) schemes are increasingly prevalent in England and Wales, partly as a result of the growth in the availability of government funding. However, insufficient research has been undertaken into the nature of these schemes and their performance, making it difficult to predict their future role. In this respect, a survey was undertaken to collect data on the background, operation, and performance of DRT schemes in England and Wales. It found that DRT schemes are often designed in an attempt to tackle social problems caused by poor accessibility and that they took time to become established, to achieve their objectives, and to reach an acceptable performance in terms of subsidy level. The paper concludes that local-authority-led DRT schemes have a role to play, but that lessons learned from schemes currently in operation must be heeded by those contemplating new scheme development.
\end{abstract}

\section{Introduction}

Numerous DRT services operate in the UK; however, their future is now uncertain as funding streams are coming to an end. The time would, therefore, seem appro- 
priate for taking stock of what the DRT schemes are doing and how they are doing it to discern a strategy for the future.

The aim of this paper is to investigate the current situation of publicly-funded DRT schemes in England and Wales. Specifically, it investigates how and why DRT schemes have been established, including data on their design and operation, the catalysts for the schemes, and their objectives. Finally, it considers the current performance of the schemes.

The following section provides a brief summary of the relevant literature followed by an outline of the method used to collect the data. This consisted of a survey sent to a carefully-selected number of local authorities who run DRT schemes. The findings from this survey are then presented along with discussion of the results and conclusions.

\section{Literature}

DRT "provides transport 'on demand' from passengers using fleets of vehicles scheduled to pick up and drop off people in accordance with their needs" (Mageean and Nelson 2003: 255). DRT has been seen as "an intermediate form of public transport, somewhere between a regular service route that uses small low floor buses and variably routed highly personalised transport services offered by taxis" (Brake et al. 2004: 324). Essentially, DRT can be defined as an intermediate and highly flexible mode of transportation giving rise to a wide variety of uses.

There are a number of reasons why DRT has become an increasingly popular transport tool over recent years. They include an increasing dissatisfaction with conventional public transport provisions (Enoch et al. 2004; Mageean and Nelson 2003), more dispersed land use patterns (Enoch et al. 2004), the lack of adaptability of conventional bus and taxi services (Ambrosino et al., 2004) and an increasing governmental interest in improved social service transport and reducing social exclusion (Ambrosino et al. 2004; Mageean and Nelson 2003).

DRT is seen by some as a tool that could fill the gap between a fixed route bus and a taxi to meet the needs of certain members of the population (Mageean and Nelson 2003). For example, Romanzzo et al. (2004) suggest that viable markets exist for DRT as an alternative transport method to be harnessed at times of weak demand, thus serving those who want to travel at these times. The role of DRT in the UK is different from the one it occupies in the U.S. due to legislative, regulatory, and market variations. 
DRT can also be used a tool to promote modal shift and increase public transport integration. There is evidence that DRT has the potential to meet the needs of niche markets, such as hospital transport (SEU 2003). Other suggested markets include shopping, commuting and leisure (Enoch et al. 2004). The Scottish Executive (2006) identified four potential categories for DRT services that encompass all of the aforementioned markets: premium value services (for example, airport transfers), high value to agency services (for example, Joblink transport), high care needs (for example, patient transport), and best value public transport (for example, rural services). The report concluded that, in Scotland, "there is potential for growth in all four main DRT markets: high care needs, high value to agency, best value and premium services, but to achieve this growth will require better targeting of public funding, resolution of some regulatory issues and improved joint working across sectors" (Scottish Executive 2006: 37).

One of the major problems facing transport planners considering DRT is the high cost of designing and running DRT services. Rural and Urban Bus Challenge funding ( $R B C / U B C$, Government funding programs aimed at increasing innovation in public transport) has been extremely useful in encouraging the set up of DRT schemes, though it is thought by some to have encouraged innovation more than cost-effective, long-term schemes. The future is still uncertain for many DRT schemes established under Bus Challenge funding (Enoch et al. 2004).

There is a suggestion that DRT schemes can prove a useful tool for attaining public policy (i.e., social, economic and environmental) goals (SEU 2003; Enoch 2004; Scottish Executive 2006) and that some funding programs-for example, the RBC/ UBC-led to a number of DRT schemes being set up. However, there is little documentary evidence referring to this type of scheme setup using challenge funding and the associated costs, benefits, and effectiveness at achieving goals.

A survey was designed to gather data to enable investigation of some of the issues raised in the literature review.

\section{Method}

The contact details for the DRT schemes were obtained from a list of registered flexibly-routed bus services operating in the UK provided by the Department for Transport (DfT). The respondents to the survey were local authority officers with responsibility for at least one DRT scheme. The survey was sent to 36 local authorities responsible for a total of 99 registered schemes. The initial responses indicated 
that some of these schemes had ceased to exist since the DfT had produced the initial list and also that some of the registered schemes were services within a single scheme rather than entities themselves. A total of 48 surveys were returned from 28 local authorities.

The survey was administered in December 2005 via email. Initial contact was made by telephone to obtain an email address. A period of two weeks was allowed before non-respondents were contacted again by phone or email.

\section{Design and Operation}

This section explores the design and operation characteristics of the schemes listed in Table 1. It begins by looking at the funding source and the geographical type of the operational area. Next, it reviews the operational characteristics including the route, the technology, the booking options, and the fare levels. Finally, it provides a summary of the design and operational lessons.

Table 1 lists contextual information about the schemes.

\section{Funding}

The majority of the scheme's funding came from the local authority or RBC/UBC grants - in a number of cases, a combination of local authority and RBC/UBC, as illustrated by Table 1. The "Other" category included money from beneficiaries of the service-for example, employers - and, in one case, a Rural Enterprise Partnership. Many of the schemes' funding was due to cease in 2007 or earlier (Table 1.). Only a very small proportion had secured funding (usually from the local authority but, in individual cases, both a developer and Kickstart were mentioned) following cessation of the original funding.

The results in Table 1 reinforce Enoch et al. (2004), which stated that Rural and Urban Bus Challenge grants had funded many DRT schemes. Two years on from the Intermode report, the results indicate that the future for many of these schemes is still uncertain.

\section{Geography}

A total of 26 of the 48 respondents questioned classified their schemes as operating in rural areas, with 7 classifying themselves in urban areas and 15 operating in a combination of area types. Figure 1 represents the split in more detail. 


\section{Table 1. Scheme Context}

\begin{tabular}{|c|c|c|c|c|c|}
\hline Location & Age, in Months & Subsidy* & No. of Vehicles & Subsidy Level & Funding Status \\
\hline \multirow{24}{*}{$\begin{array}{c}\text { Rural } \\
(26)^{* *}\end{array}$} & \multirow[t]{5}{*}{$0-12(6)$} & \multirow[t]{4}{*}{ DfT (5) } & $1(1)$ & \multirow[t]{2}{*}{$£ 5+(2)$} & Ongoing (1) \\
\hline & & & $2(2)$ & & March 2008 (1) \\
\hline & & & $3(1)$ & \multirow[t]{2}{*}{$£ 2-£ 5(2)$} & Ongoing (1) \\
\hline & & & $4(1)$ & & March 2005 (1) \\
\hline & & LA (1) & $1(1)$ & $£ 5+(1)$ & Unknown (1) \\
\hline & \multirow[t]{8}{*}{$12-24(9)$} & \multirow[t]{14}{*}{$\mathrm{DfT}(15)$} & \multirow[t]{5}{*}{$1(5)$} & $£ 2-£ 5(1)$ & $2007(1)$ \\
\hline & & & & \multirow[t]{3}{*}{$£ 5+(3)$} & March 2007 (1) \\
\hline & & & & & $2007 / 8(1)$ \\
\hline & & & & & Unknown (1) \\
\hline & & & & Unknown (1) & March 2007 (1) \\
\hline & & & $2(1)$ & \multirow[t]{2}{*}{$£ 5+(2)$} & March 2006 (1) \\
\hline & & & $5(1)$ & & July 2006 (1) \\
\hline & & & Unknown (2) & \multirow[t]{2}{*}{$£ 2-£ 5(3)$} & Unknown (2) \\
\hline & \multirow[t]{2}{*}{$24-36(2)$} & & \multirow[t]{2}{*}{$1(2)$} & & March 2006 (1) \\
\hline & & & & $£ 5+(1)$ & Ongoing (1) \\
\hline & \multirow[t]{5}{*}{$36-48(5)$} & & $1(1)$ & $£ 2-£ 5(1)$ & $2005(1)$ \\
\hline & & & $2(2)$ & \multirow[t]{5}{*}{$£ 5+(5)$} & Ongoing (1) \\
\hline & & & & & $2006 / 7(1)$ \\
\hline & & & $5(1)$ & & Ongoing (3) \\
\hline & & LA (1) & $1(1)$ & & \\
\hline & $48-60(1)$ & \multirow[t]{3}{*}{ DfT (3) } & $5(1)$ & & \\
\hline & \multirow[t]{3}{*}{$60+(3)$} & & $2(1)$ & $£ 2-£ 5(1)$ & $2005(1)$ \\
\hline & & & $4(1)$ & $£ 5+(1)$ & Ceased (1) \\
\hline & & None (1) & $2(1)$ & $£ 0$ (1) & Unknown (2) \\
\hline \multirow{4}{*}{$\begin{array}{c}\text { Rural, } \\
\text { Suburban } \\
\text { (4) }\end{array}$} & $0-12(1)$ & LA (1) & \multirow[t]{3}{*}{$1(3)$} & $£ 2-£ 5(1)$ & \\
\hline & $12-24(2)$ & \multirow[t]{18}{*}{ DfT (18) } & & $£ 5+(1)$ & March 2007 (1) \\
\hline & & & & $£ 2-£ 5(2)$ & Ongoing (2) \\
\hline & $60+(1)$ & & $6(1)$ & & \\
\hline \multirow{2}{*}{$\begin{array}{c}\text { Rural, } \\
\text { Urban (2) }\end{array}$} & $24-26(1)$ & & Unknown (1) & \multirow[t]{2}{*}{$£ 2-£ 5(2)$} & Unknown (1) \\
\hline & $48-60(1)$ & & $4(1)$ & & March 2006 (1) \\
\hline \multirow{4}{*}{$\begin{array}{c}\text { Rural, } \\
\text { Urban, } \\
\text { Suburban } \\
\text { (4) }\end{array}$} & $0-12(1)$ & & $1(2)$ & $£ 0-£ 2(1)$ & Ongoing (1) \\
\hline & $12-24(2)$ & & & $£ 5+(1)$ & January 2007 (1) \\
\hline & & & $10(2)$ & $£ 2-£ 5(1)$ & Ongoing (3) \\
\hline & $60+(1)$ & & & $£ 5+(1)$ & \\
\hline Urban, & $0-12(4)$ & & $1(1)$ & $£ 2-£ 5(1)$ & \\
\hline Suburban & & & $2(2)$ & $£ 5+(2)$ & March 2008 (1) \\
\hline & & & & & Ongoing (1) \\
\hline & & & $4(2)$ & $£ 2-£ 5(2)$ & Dec 2004 (1) \\
\hline & $36-48(1)$ & & & & October 2004 (1) \\
\hline Urban (7) & $0-12(1)$ & & $1(2)$ & $£ 5+(2)$ & Ongoing (1) \\
\hline & $24-36(4)$ & & & & August 2006 (1) \\
\hline & & & $2(1)$ & $£ 2-£ 5(3)$ & Nov 2005 (1) \\
\hline & & & $3(1)$ & & May 2006 (1) \\
\hline & & Other (1) & $6(1)$ & & Ongoing (1) \\
\hline & $36-48(2)$ & $\operatorname{DfT}(2)$ & $2(1)$ & $£ 5+(1)$ & Unknown (1) \\
\hline & & & $5(1)$ & $£ 2-£ 5(1)$ & Ceased (1) \\
\hline
\end{tabular}

* "DfT" refers to schemes of an element of funding from special UK Department for Transport grants, e.g. Rural Bus Challenge, Urban Bus Challenge, or Rural Bus Subsidy Grant. These include schemes where local authorities also input money. "LA" refers to schemes funded by the local authority where no DfT money was used. "Other" refers to grants from non-government sources. "None" refers to schemes that are not subsidized.

** Numbers in parentheses refer to frequency of occurrences. 


\section{Figure 1. Geographical Distribution of Schemes}

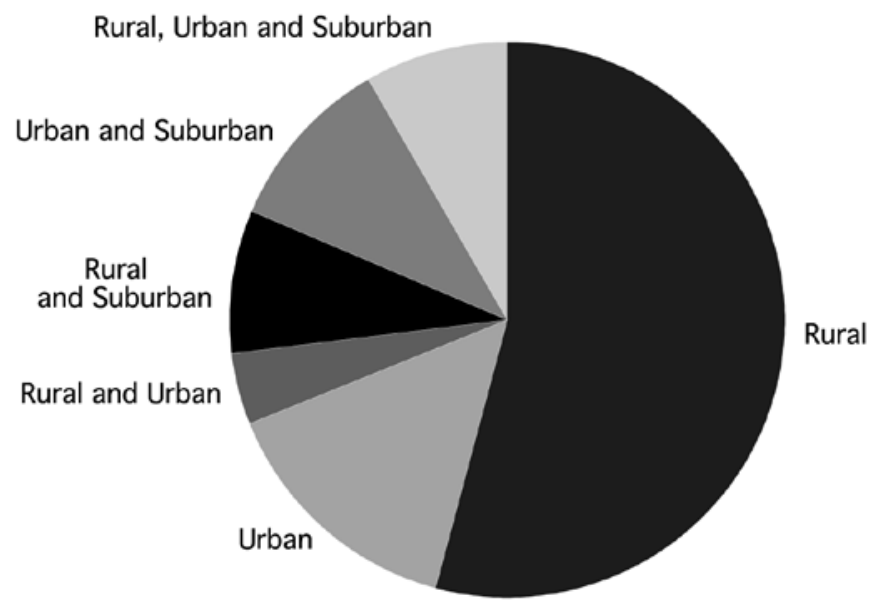

The schemes are spread across seven of the English regions, with one scheme in Wales. A total of 4 of the schemes operated in the East of England, 7 in the East Midlands, 2 in the West Midlands, 11 in the North West, 14 in the South West, 8 in the South East, and 1 in Yorkshire and Humberside.

\section{Route and Schedule}

The schemes exhibit three different types of route: fully-flexible, semi-flexible, and fixed and flexible. Those that were fixed and flexible were generally time (demand) dependent, operating on a flexible basis off peak and a fixed basis when demand was higher at peak times. The semi-flexible services often had fixed routes in busier areas and flexible sections off route in areas of lesser demand.

\section{Operating Hours}

Most of the schemes operated over six days during the daytime and evening. A few exceptions operated on a Sunday or 24 hours a day. A total of 14 of the 43 schemes that gave their operating hours operated for between 41 and 60 hours per week, with 61-80 hours per week also being common operating hours. Four schemes operated in excess of 120 hours.

\section{Vehicles}

The fleet sizes of the schemes are displayed in Table 1. Schemes usually had 8-16 seat vehicles that were manufactured by Volkswagen, Mercedes or Roehill. The most common number of seats per scheme was 11-20, followed by schemes with $50+$ seats and $21-30$ seats. The schemes with $50+$ seats were most common in 
rural areas. In all seat number bands excluding 31-40, there was an even split between those schemes operating on a fully-flexible basis and those operating on a semi-flexible basis. Furthermore, the majority of vehicles in each category except 31-40 seats were operating on an on-demand basis.

\section{Technology}

A total of 29 of the 45 schemes that responded to this question used booking and routing software, mainly Mobisoft with some using Trapeze or other alternatives. Slightly over half of the schemes in rural areas did not use any specialized software, instead relying on pencil and paper booking or taxi software. Of those with software, five used Mobisoft, two used Trapeze, and two used other software. All but one of the schemes in urban areas used some kind of booking software, usually Mobisoft. None of the schemes with 1-10 seats used any software. Of those schemes with 11-20 seats, 9 of the 14 schemes used software or some kind. Only 1 of the 6 schemes with 21-30 seats and 11 of the 24 schemes with 50+ seats used software of any kind.

Schemes with fully-flexible routes were more likely than those with semi-flexible routes to make use of software as were those that operated on-demand as opposed to in any other way.

\section{Booking}

Figure 2 shows the booking options the DRT schemes offered.

\section{Figure 2. Scheme Booking Method(s)}

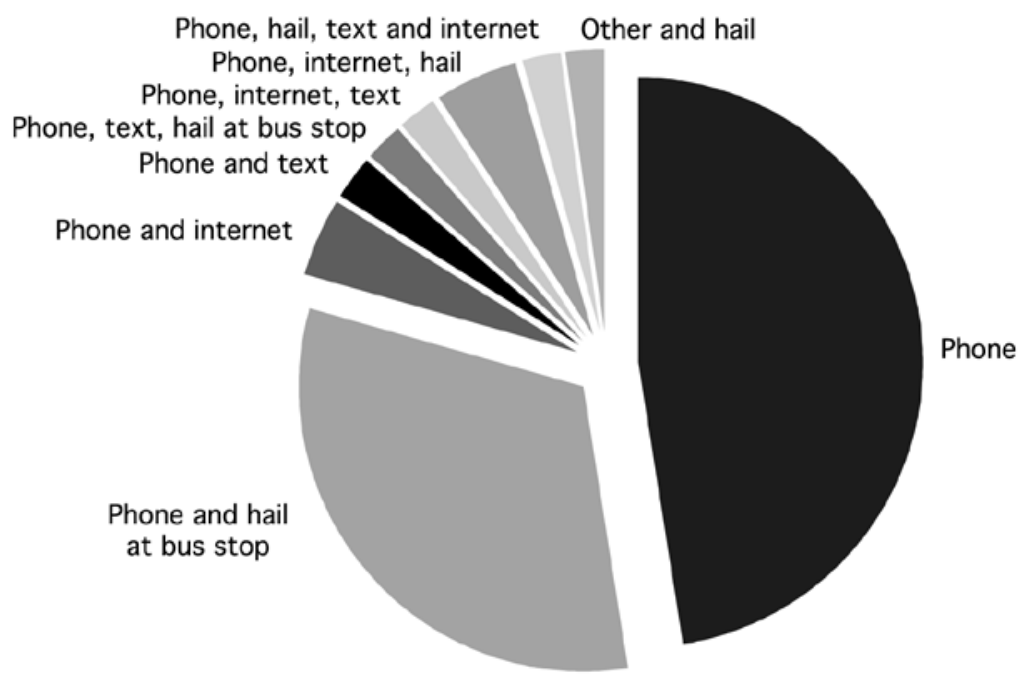


Most of the schemes offered phone booking often with hailing at a bus stop. Text message and internet booking were not common; however, a portion of the services did have websites featuring timetables and information.

\section{Fares}

Most of the schemes had variable fares (Table 2) based both on journey length and passenger type. The fares ranged from $£ 0.30$ for a single journey to $£ 4.00$ for a return, with one service offering a longer cross-county journey priced at $£ 12.00$ for an adult return. Those services with flat fares ranged from $£ 0.70$ for a single to $£ 5.00$ for a return journey with the average being $£ 1.00-£ 1.50$ for a single ticket. Less than half of the services offered a season ticket.

\section{Table 2. Fare Type}

\begin{tabular}{|c|c|c|c|}
\hline Fares & Response Rate & $\begin{array}{l}\text { Variable Fare } \\
\text { Based on: }\end{array}$ & $\begin{array}{c}\text { Season Ticket } \\
\text { Offered }\end{array}$ \\
\hline Flat & 11 & N/A & $\begin{array}{l}\text { Yes: } 4 \\
\text { No: } 7\end{array}$ \\
\hline Variable & 34 & $\begin{array}{c}\text { Journey length: } 9 \\
\text { Passenger type: } 3 \\
\text { Both: } 22\end{array}$ & $\begin{array}{l}\text { Yes: } 17 \\
\text { No: } 17\end{array}$ \\
\hline
\end{tabular}

\section{Design and Operational Lessons}

This section discusses the problems with which respondents were faced and reviews changes to the design or operation of the scheme they would make with hindsight.

\section{Design and Operation: Problem Issues}

The respondents highlighted a wide range of problems with the design and operation of the DRT schemes ranging from problems with the users ("some local community groups felt that it should be for their specific use and not for the general population" and "high public expectations can make the scheme difficult to deliver; people expect it to do everything all the time") to problems with getting tender bids ("few available taxi operators in the area lead to a small choice from the tender round") and problems with technology ("initially, when introducing the scheme, we did not have the computer software in place in time to give us enough time to design a system"). Respondents had also experienced problems with building an acceptable level of patronage, vehicle breakdowns, reliability issues, integration into an established commercial network, and limitations of booking systems.

\section{Design and Operation: Changes}

Ideas about changes to design or operation ranged from "not much, as the scheme has gone from strength to strength" to "try something else!" However, other 
responses were more specific and concerned elements of the design of the schemes such as "simplify the timetable and route, promote the interchange possibilities more, make more of the scheme demand responsive, provide more localised information for each village" and "make it far more flexible with even less timing points from the start." Others concerned more peripheral issues paramount to the schemes success, such as "start promotion and awareness raising six months before launch," "more meetings with rural residents in the early stages of the scheme," and "make sure there is enough lead in time before the scheme goes operational." Finally, some of the changes were in relation to the operator side of the scheme, for instance, "set up in an area where more taxi operators are willing to try a service" and "build partnership with the Taxi/PHV operators and develop a scheme with them."

\section{Catalysts and Objectives}

This section initially examines the catalysts indicated by the respondents for selecting DRT as a transport tool. The respondents were asked to state what had motivated them to design and implement a DRT scheme. Catalysts differ from objectives because they are why DRT was chosen rather than what the DRT scheme was trying to do. Figure 3 illustrates the spread of responses. The respondents were able to choose multiple answers to this question and were asked to justify their responses. These justifications are discussed in more detail below.

\section{Figure 3. Scheme Catalysts}

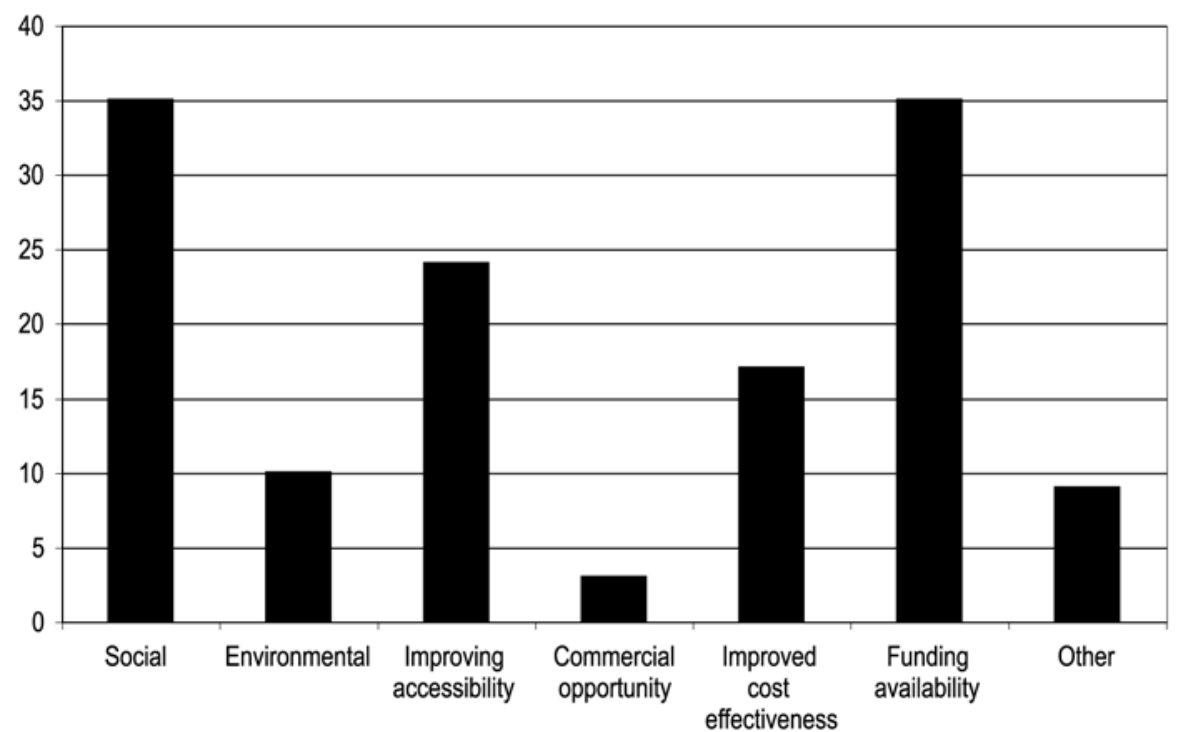




\section{Scheme Catalysts}

\section{Social}

Many of the respondents cited social catalysts for commencing the scheme. The qualifying reasons given for this choice were wide ranging, from the all-encompassing "to give otherwise excluded people a choice" to more specific statements that centered on providing a travel option to reach activities and services, for example, "provision of transport service to supermarket, cinema, etc." and "provide access to services and facilities for a wide range of people." Some of the justifications centered around the type of users, for example, "to provide a specialised service for older shoppers." The responses illustrated that characteristics can be widely variable.

\section{Environmental}

Many of the schemes also had environmental motivations centered around reducing the use of the private car "to reduce the need for a second car" and "to aid a reduction in car usage," "encourage public transport usage by reducing car dependency," and "to encourage modal shift away from the car in an environmentally sensitive area," and, in a similar vein, "to reduce car use in rural areas," "to encourage modal shift by serving destinations not previously covered by public transport," and "to encourage a shift away from the private car."

\section{Increased accessibility}

The respondents who chose this category justified their choice in a number of ways, for example, "DRT allows for a door-to-door service to be offered" and allows transport to access "otherwise isolated residents." Furthermore, it can be operated using "fully accessible buses" and can easily be used to provide a feeder service to "onward transport connections."

The flexibility offered by DRT services in relation to both scheduling and routing made some respondents believe it would improve accessibility in an area, as indicated by statements such as "DRT can operate at periods of low demand" and "it can offer a combination of fixed bus route at scheduled times and provide flexible demand responsive transport in between." One respondent simply stated that DRT was "more flexible," others were more expressive. It was thought by one respondent that DRT would offer "more flexible routes" or, from another angle, "fixed route services would not give the flexibility required."

\section{Commercial Opportunity}

Three respondents recognized the commercial opportunity of operating the DRT service for the local area, citing reasons such as "to keep people using local shop- 
ping facilities rather than travelling further afield" and "to promote sustainable tourism in rural areas and encourage use of local shops."

\section{Improved Cost Effectiveness}

Certain respondents were operating the services to see if it could provide the same or better level of service than conventional transport tools for the same or reduced costs, for example, "to see if higher levels of service and flexibility can be offered for the same cost as a conventional bus" and cutting costs by using "suitably-sized vehicles to meet demand." It was also stated that DRT offered reduced costs because "it would only travel when needed" and it could be "integrated with special needs and schools transport." One respondent stated that it offered improved cost effectiveness because "even a limited service each day is better than no service." It was predicted that DRT could provide a cost-effective transport solution in "deep rural areas that are not conducive to operating a conventional bus service." This is further illustrated by the response, "the need for a bus service to cover a large rural area that provides a cost-effective service for the whole community." For some, DRT is seen as a way of making "the most cost-effective use of the available resource."

\section{Funding Availability}

The second most popular response was the availability of funding. Of the 26 respondents who gave a qualifying statement for selecting funding availability as a motivation, 25 mentioned either RBC or UBC in their qualifying statement. The only respondent who did not mention $\mathrm{RBC}$ or UBC cited "limited funding availability in small rural area" and was 100 percent funded by the Rural Bus Subsidy Grant.

\section{Other}

Nine respondents cited other reasons for choosing to operate DRT. These included "based on our experience with other services," "to allow us to provide transport to pockets of isolation and feed into public transport through a network scheme," and because "DRT is seen as a regeneration tool."

Three of the schemes were set up to "test out DRT in the area," for example, "by using a taxi-based solution and to find evidence of support for an evening taxibased flexible service." Although few of the respondents explicitly stated that DRT is an experimental concept for them, this is apparent in some of the responses. 


\section{Scheme Objectives}

Each respondent was asked to identify the objectives of their scheme, that is, what the scheme was specifically set up to do, and to rate to what extent the objectives were being achieved. Most of the respondents had between four and six objectives. The objectives were split into four categories: social, environmental, economic, and geographical, as seen in Table 3. The objectives have been categorized by their primary purpose, for example, improving access to fresh food could be a social or economic objective. Where the objective states that the scheme aims to "provide access to food shopping for older and disabled people," the objective would be classified as social because, although the service would increase patronage of local shops, this is a secondary benefit of the objective. Where the objective states that it intends to "provide a service for tourists to visit the historic market town," it would be classified as economic, although it also has social benefits for those without a car and environmental benefits by providing a more sustainable transport option for those with access to a car. This method has been used during the categorization of all the objectives but the classifications are very subjective.

Table 3. Objective Category

\begin{tabular}{lc}
\hline Objectives & Response rate \\
\hline Social & 129 \\
Environmental & 12 \\
Economic & 16 \\
Geographical & 12 \\
\hline
\end{tabular}

\section{Social}

The majority of the objectives fitted into the social category, ranging from the unspecific, such as "promote social inclusion," "reduce rural area social exclusion," and "provide public transport for socially-excluded rural residents," to the specific, such as "to use the project to forge closer links with local community groups and involve these in defining and developing the services," "to engage a community which currently has no realistic public transport," and "enhance the quality of rural life by giving greater independence to youngsters, the elderly, and the mobility impaired." The majority of the social objectives related to increasing accessibility to locations that were currently inaccessible. This is illustrated by the following objectives: "access to food shopping for older and disabled people," "to provide people without private transport access to jobs," and "to provide access to essential facilities for the local community." 


\section{Environmental}

Twelve schemes had some environmental objectives, although none had solely environmental objectives. Examples included "modal shift," "sustainable transport," and "to help address environmental problems caused by individual car ownership using by providing sustainable modes." Where schemes had one or more environmental objective, it was never the primary objective. In most cases, the environmental objective was secondary or something that would occur as a result of increased bus use. For example, Scheme 4 had six objectives, both social and economic, except one which was to "reduce traffic into the rural villages and tourist spots." However, this objective is not purely environmental because reducing traffic also has social benefits.

\section{Economic}

None of the schemes had primarily economic objectives; they were often secondary benefits attributable to social objectives. Improving access to facilities and services inherently has economic benefits (i.e., by improving access to jobs and by improving access to facilities such as shops). Some examples of economic objectives were "to provide the most cost-effective service for those remoter areas," "to provide a cost-effective service that balances patronage to service provision," "to use existing taxi provision in the area more efficiently," and "to meet employer demand for workers due to expansion." It appears that the social objectives would offer long-term economic benefits, but this was not explicitly stated.

\section{Geographical}

The objectives classified as geographical were those that referred to providing a service to an area without bus services but made no mention of a social group or access to a specific service or activity. The primary objective of six of the schemes fit into the geographical category. This was usually due to the perception that DRT could provide a service tailored specifically to the geography of the area. Examples of these objectives included "provide the remoter areas with some level of service," "low cost access from the rural area using taxi provision," and "increase local bus services to small rural communities which generated low levels of passenger usage."

\section{Current Performance}

This section discusses the subsidy levels and financial sustainability of the schemes and their performance in terms of their objectives. Finally, it will discuss the overall performance of the schemes in terms of subsidy level and objective achievement. 


\section{Subsidy Level}

Table 1 showed that the majority of the schemes were operating at a subsidy level exceeding $€ 2.00$ per passenger trip, with slightly over half having a subsidy exceeding $£ 5.00$ per passenger trip. Subsidies of $£ 2.00-£ 5.00$ are viewed as an acceptable level within the industry, based on the cost of operating conventional bus services, although this is locally variable. Only one of the respondents' schemes was breaking even.

Figure 4 shows that those schemes operating in a purely rural area had a higher incidence of subsidies exceeding $£ 5.00$ and a lower incidence of subsidies falling into the $£ 2.00-£ 5.00$ range than those operating in an urban or mixed area. In addition, schemes with less than 21 seats were more likely to have higher subsidies than larger schemes.

\section{Figure 4. Comparison of Subsidy Level and Geographic Characteristics}

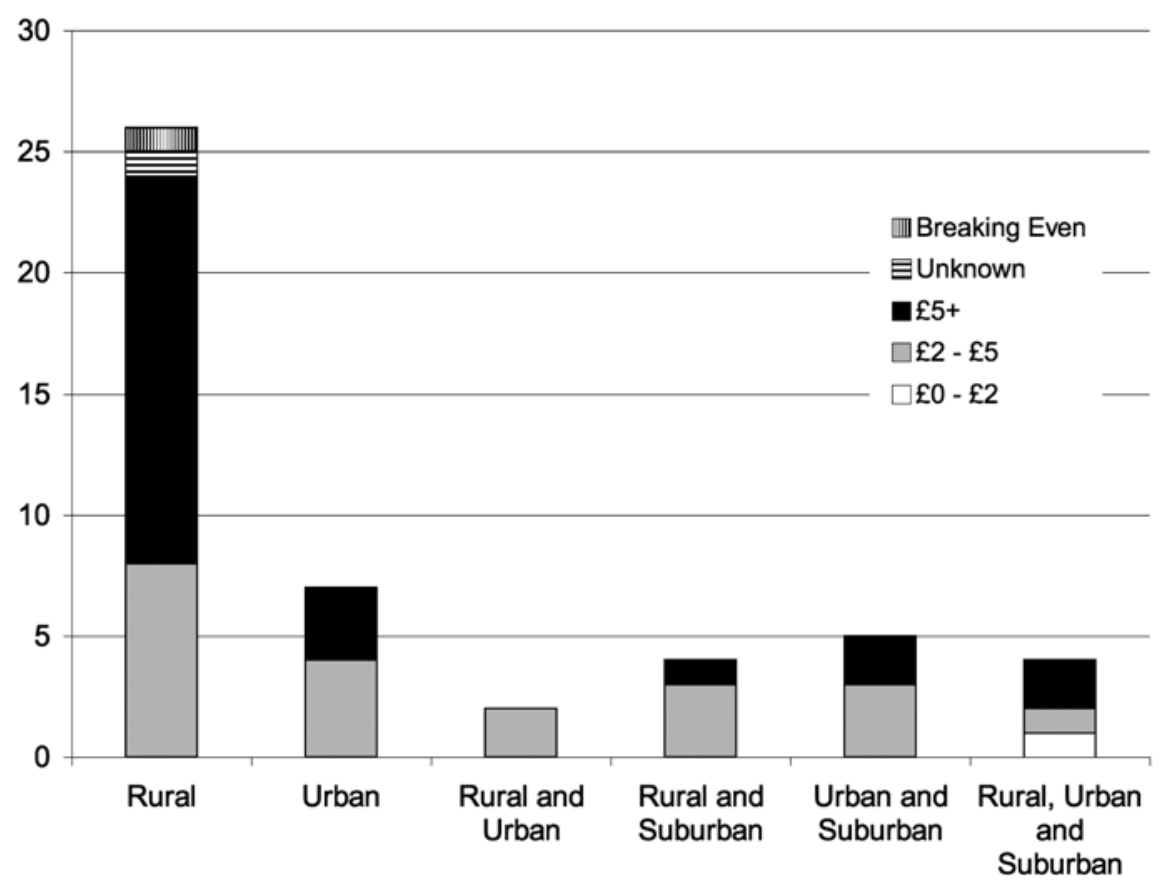

Whether the scheme offered a season ticket had strongest bearing on the subsidy levels. A total of 14 of the 21 schemes that offered season tickets were in the $£ 2.00-£ 5.00$ subsidy range. Conversely, 18 of the 24 schemes that did not offer any kind of season ticket had subsidies above $£ 5.00$. 


\section{Financial Sustainability}

All the respondents to this question were confident that the schemes would achieve financial sustainability in the medium (1-3 years) or long (3+ years) term. In total, 28 of the 48 that responded to this question were hoping to achieve financial sustainability within the next three years. This included all the schemes that operated in solely urban areas and rural and suburban areas. It also included half of those operating in a rural area.

\section{Objective Achievement}

All of the schemes had some social objectives, so it is difficult to define the objective most likely to be achieved; suffice it to say that the schemes had a higher achievement rate for the objective listed first. Figure 5 illustrates the average level of objective achievement across the schemes. This was calculated by taking the percentage the respondent felt each of the scheme's objective's was being achieved and dividing it by the number of objectives. All but one of the schemes achieved in excess of 40 percent of their objectives. Only one scheme had a 100 percent objective achievement rate (Scheme 3). It must be noted, however, that the numbers reported here are a reflection of the opinions of the scheme managers regarding the extent to which they had achieved their objectives.

Reasons given for not achieving objectives ranged in generality. For example, respondents regarded a lack of demand for the service as a main factor in its failure to achieve the objectives: "very limited demand for the service in practice," "patronage remains low because many employees are being recruited from outside the area in which the service operates," "few journeys being made to employment areas, which was the main reason for the previous bus route extension," "problems increasing demand and usage of the services provided," "not all areas can provide sufficient users to fill the vehicle," and "the service is falling well short of anticipated success, possibly because, although the area is deeply rural, it is inhabited mostly by commuters who have more than one car per household and therefore do not suffer the perceived isolation." Although one scheme had the opposite problem ("the door-to-door aspect of the service had proved to be so popular that, on some occasions, people have had to be turned down; therefore, some people who need the service are not using it." Five of the respondents had problems overcoming psychological barriers, for example, "in line with other experiences, people are unwilling to take two buses for a journey as there is a perceived potential problem" and "patronage levels are low and, although we are unsure of 


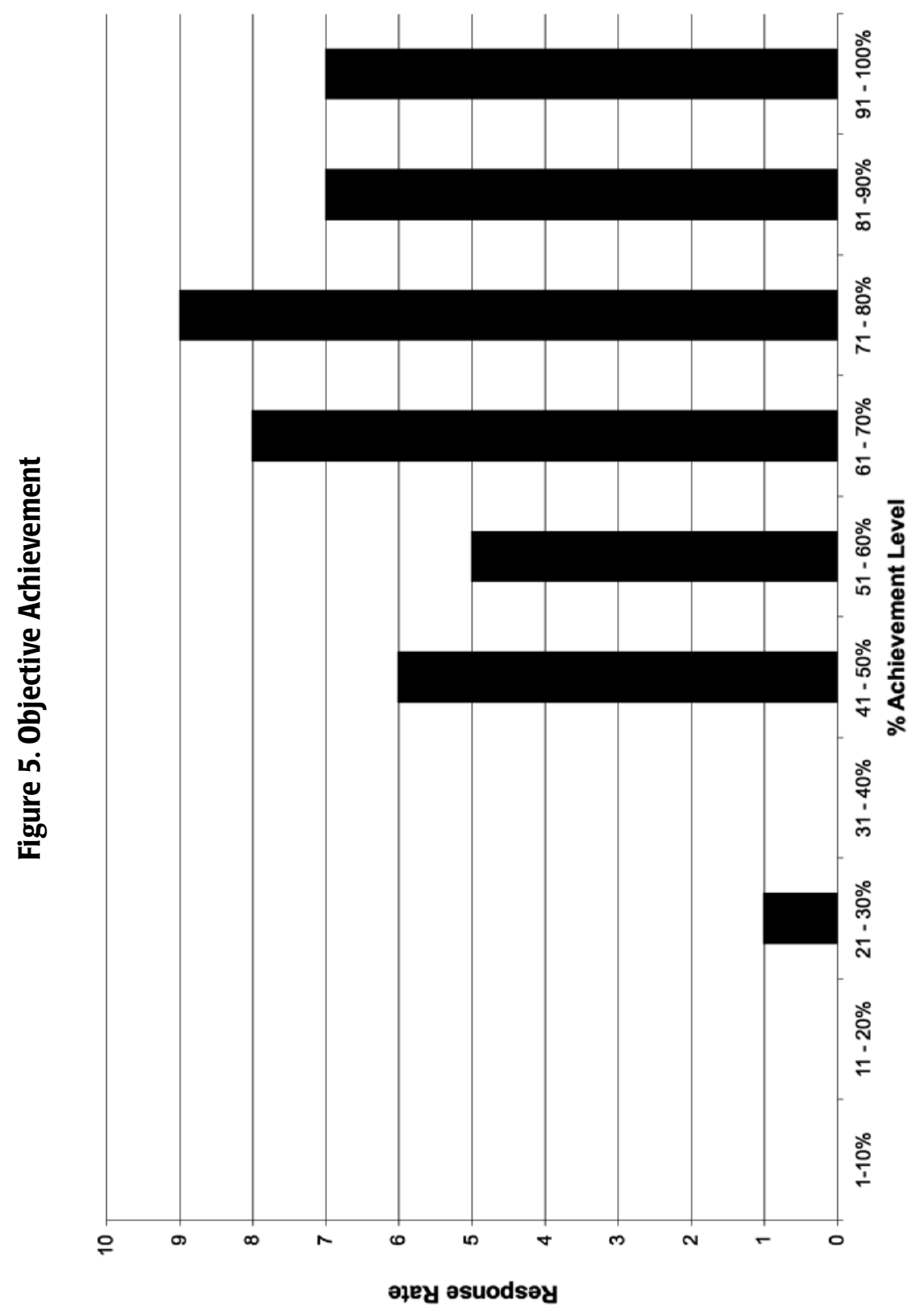


why, we believe it is due to people lacking confidence in using something new and different and taking time to grasp the concept."

Finally, seven respondents had low achievement rates due to the recent start of the scheme. These respondents hoped to attain higher achievement levels in the future, for example, "the scheme has only just started running" and "the route has only just become fully demand responsive."

\section{Overall Performance}

This section attempts to identify the characteristics common to the more or less successful DRT schemes.

Those that have been classified as more successful have lower subsidy levels and higher objective achievement, the converse being true for those classified as less successful.

The more successful schemes generally used some form of DRT technology, and many of them offered more that one booking option. These schemes had generally been established for longer than the less successful schemes and also were likely to operate for an above-average number of hours. Finally, they were more likely to be based in an area that was not purely rural.

The less successful schemes were likely not to use any DRT technology and usually offered fewer booking options. Many of the schemes operated for fewer hours than average. These schemes had generally been operating for a shorter time and were more likely to be in a rural area.

\section{Conclusion}

In terms of design and operation, most of the schemes were based in rural areas. The funding came predominantly from Rural or Urban Bus Challenge Grants, and they were usually high technology. The main lessons those running the DRT schemes had learned from the process was that DRT must have sufficient time invested at the planning stage and that the design used must not be over-complicated and must fit the purpose.

The survey revealed that most DRT schemes included in this study were established for two reasons: the availability of funding for innovative transport solutions and to impact social policy goals that could be influenced by improved accessibility. The data indicated that many of the schemes have been partially successful in achieving these goals. However, for those that were struggling to achieve the goals, 
there are some common problems. These include generating sufficient demand and surmounting psychological barriers of prospective users.

DRT schemes included in this research are trying to meet social policy goals. However, what is poignant is that those involved in the schemes feel they have a valuable role to play. Although the data do not fully support this assertion at present, it has created a base on which to develop further research into the merits or otherwise of publicly-funded DRT schemes in England and Wales. Furthermore, it makes the tentative suggestion that, in the right place, at the right time, and with the right planning, DRT could be a valuable tool in the future.

\section{References}

Ambrosino, G., J. Mageean, J.D. Nelson, and M. Romanazzo. 2004. Experience of applications of DRT in Europe. In Abrosino, Nelson, and Romanazzo (eds.). 2004. Demand responsive transport services: Towards the flexible mobility agency. Italy: ENEA.

Brake, J., J.D. Nelson, and S. Wright. 2004. Demand responsive transport: Towards the emergence of a new market segment. Journal of Transport Geography 12: 323-337.

Enoch, M., S. Potter, G. Parkhurst, and M. Smith. 2004. Intermode: Innovations in demand responsive transport. UK: DfT.

Mageean, J. and J.D. Nelson. 2003. The evaluation of demand responsive transport services in Europe. Journal of Transport Geography 11: 255-270.

Romanzzo, M., G. Ambrosino, and J.D. Nelson. 2004. Actions for a sustainable urban mobility. In Abrosino, Nelson, and Romanazzo (eds.). 2004. Demand responsive transport services: Towards the flexible mobility agency. Italy: ENEA.

Scottish Executive: Derek Halden Consultancy, The TAS Partnership, and the University of Aberdeen. 2006. Review of demand responsive transport in Scotland. Transport. Research Planning Group, Social Research, Scottish Executive, Edinburgh, June. Visit http://www.scotland.gov.uk. Last accessed 30 September 2006.

Social Exclusion Unit. 2003. Making the connections: Final report on transport and social exclusion. London: ODPM. 


\section{About the Authors}

ReBeCCA LAWS (r.laws@lboro.ac.uk) completed a BSc in Geography at Hull University and is researching for a PhD at Loughborough University into the evaluation of DRT schemes in England and Wales. She is currently employed at a transport consultancy that specializes in sustainable transport.

DR. MARCuS ENOCH (m.p.enoch@lboro.ac.uk) is a Senior Lecturer in Transport Studies at Loughborough University in the UK, where he has worked since transferring from a postdoctoral research fellowship at the Open University in January 2003. He has particular research interests in the implementation, financing and operation of transport demand management measures; factors affecting the efficiency and effectiveness of buses, demand responsive transport systems, and car clubs; and transport within small island developing states. He has conducted a number of research projects over the last decade for clients including the European Commission, UK government departments, UK local authorities, and UK academic research councils. He is also a freelance transport news and photo journalist.

Stephen Ison (s.g.ison@lboro.ac.uk) is Professor of Transport Policy at Loughborough University. He obtained an MA in Transport Economics from ITS, Leeds and $\mathrm{ahD}$ in road user charging and implementation from Loughborough University. He has 20 years' experience in transport research, mainly in the areas of transport policy and economics. He has published more than 50 articles in the area of transport policy and a number of books, most recently Road User Charging: Issues and Policies (Ashgate 2004) and Implementation and Effectiveness of Transport Demand Management Measures: An International Perspective (Ashgate 2008).

STEPHen POTTER (s.potter@open.ac.uk) is the Professor of Transport Strategy at the Open University. He has undertaken research and teaching work on a variety of transport subjects, including best practice demand responsive bus services, new sources of funding for local transport initiatives, public and policies to promote low carbon transport systems. He is a member of the Green Fiscal Commission and the taxation working group of the National Business Travel Network. His work for Transport for London on professional development for Travel Planners has led to the new OU CPD Certificate in Travel Planning. 